\title{
TE QUIERO CAYAMBE: CAMPAÑA MARCA CIUDAD
}

\section{LOVE YOU CAYAMBE: CITY BRANDING CAMPAIGN}

\author{
Lourdes Calderón Garrido \\ Universidad Tecnológica Israel, Ecuador \\ Diana Gabriela Toapanta Espín \\ Universidad de Salamanca, España
}

\section{RESUMEN}

El tardío interés del Ecuador por trabajar en una marca ocasionó que las ciudades más pequeñas, como Cayambe, también retrasen la construcción de las suyas. Debido a esto, el desarrollo turístico no se ve favorecido en los últimos años, mellando en el crecimiento de la inversión y los negocios. En este trabajo, se realiza un diagnóstico de la actual situación turística de la ciudad de Cayambe, así como de otros referentes, con la finalidad de proponer una marca ciudad que se posicione gracias a una estrategia publicitaria visual y tácticas transmedia que logren impacto; todo acorde con los fines e intereses de la ciudad y sus habitantes.

Palabras clave: turismo, Cayambe, publicidad, marca ciudad, transmedia, comunicación.

\begin{abstract}
The late interest of Ecuador to work on a brand caused that smaller cities also delay their own brand. This did not favor their tourism development, as well as the growth of investment and business. This article is a diagnosis of the current tourist situation of Cayambe, as of other references, proposing the creation of the city branding. Regarding its positioning, a visual advertising strategy that impacts the objectives of the city and its inhabitants through transmedia tactics, is suggested.
\end{abstract}

Keywords: tourism, Cayambe, advertising, city brand, transmedia, communication.

Este es un artículo Open Access bajo la licencia Creative Commons AtribuciónNoComercial-Compartirlgual 4.0 


\section{Introducción}

En el año 2013, Ecuador logra construir su marca país con mayor impacto significativo, y se sigue trabajando en el posicionamiento de marca, ya que es prácticamente nueva. Las propuestas que se presentaron, en todas las fases de creación, no contaron con la participación de los grupos, colectivos y los propios ciudadanos ecuatorianos, principales interesados (Marzano, 2012). De forma similar ocurre en ciudades pequeñas que no cuentan aún con una marca que los represente o que sea reconocida por sus habitantes. El problema radica, no solo en la construcción de las marcas, ya que algunas sí se han creado, sino en la identificación de la marca con la ciudad y también en la difusión y estrategia comunicacional.

Los gobernantes de las ciudades pequeñas no les dan importancia a los nuevos canales de comunicación y se mantienen en los tradicionales, con la misma forma discursiva o de dar el mensaje. Por lo tanto, se requiere analizar la situación actual de las marcas de las ciudades pequeñas y su impacto turístico; definir si es necesaria la reconstrucción de la marca y diseñar una nueva estrategia publicitaria.

Cayambe, es considerada una ciudad pequeña pero turísticamente con una importante proyección. En este estudio, se analizan los códigos culturales y supuestos sociales de esta ciudad, para establecer los elementos prioritarios a visualizar en la narrativa de un anuncio publicitario o spot en el que se promociona el turismo y la marca de la ciudad.

La información económica, turística, social y cultural de la ciudad es de vital importancia para situarse en el contexto. Además, los resultados de la encuesta y del método histórico-lógico, en este estudio, son la base significativa. Con los datos obtenidos se trabaja en el guion del producto audiovisual, el mismo que se incorpora como parte de una estrategia comunicacional con el concepto de transmedia y el modelo publicitario de acuerdo a los principios de Jenkins y Thorburn (2003): la convergencia mediática, la inteligencia colectiva y la cultura participativa.

\section{Marco teórico}

En el año 2001, Ecuador intenta por primera vez una marca país que se leía así: «La vida en estado puro», teniendo como objetivo principal representar una imagen natural del país; lamentablemente no tuvo tanta fuerza de impacto turístico, ni logró recordación de marca dentro o fuera. En el año 2010, se redefinió la marca con el fin de convertir al Ecuador en potencia turística, con elementos del Sumak Kawsay (palabra quechua, que se refiere a la cosmovisión ancestral de la vida); es así que nace el eslogan «Ecuador ama la vida».

En noviembre de 2013, se impulsa un proceso de revalorización de la misma, enfocándose en los productos exportables y en la mejor forma de exponer el orgullo de ser ecuatoriano, por lo que en 2014 se lanza la marca «All you need is Ecuador». El impacto de esta marca país se demuestra en la obtención de algunos óscares del turismo (llegando a 14, y en 2017 se logró un record); los reconocimientos se deben a ciudades como Quito, Cuenca, Galápagos y Guayaquil, seleccionadas como líderes, principalmente en el área de destinos; con seis hoteles premiados ubicados en esas ciudades, y se suma el tren crucero, nombrado el mejor tren de Sudamérica. 
La gestión de la marca ha permitido un crecimiento económico para el país. El turismo se constituye así en la tercera fuente de ingresos no petroleros en el Ecuador y contribuye con el 2.1\% del PIB (World Travel Tourism Council, 2017). La importancia del turismo en los últimos años para el Ecuador, incide en la generación de más fuentes de empleo cada año.

En 2017, TripAdvisor posicionó las diez mejores ciudades para visitar en el Ecuador, entre las cuales se encuentran Quito, Cuenca, Guayaquil, Baños, Montañita, Puerto Ayora, Salinas, Otavalo y Loja. De todas ellas, Quito es una de las ciudades con más proyección turística.

Quito, pertenece a la provincia de Pichincha, que está conformada por ocho cantones: San Miguel de los Bancos, Pedro Vicente Maldonado, Puerto Quito, Cayambe, Pedro Moncayo, Mejía, Rumiñahui y Distrito Metropolitano de Quito. De estas ocho ciudades la que más destaca es Quito, capital del país.

Según reporte del gobierno provincial de Pichincha, entre el 2010 y 2011, las visitas de turistas internacionales a la provincia fue de 44\%; de ellos el 41.01\% eligió como destino Quito; solo 0.07\% eligió Cayambe y 0.63\% Mindo. Sin embargo, $41 \%$ de los turistas residentes eligen Quito y 0.07\% Cayambe. Con referencia al turismo interno, 28\% de turistas son los mismos pobladores de Pichincha, quienes viajan al interior; seguido de Cayambe con 7.59\%, Sangolquí con 5.75\%, Mindo con 3.53\% y Puerto Quito con 3.07\%. Las cifras ponen a Cayambe en segundo lugar en la elección de un destino turístico de la provincia de Pichincha. Por lo tanto, es necesario potenciar su desarrollo turístico con una estrategia publicitaria específica, considerando elementos propios de la ciudad. Una vez realizado el diagnóstico es posible construir la identidad y a su vez una marca ciudad, y de esta manera, generar la estrategia publicitaria.

\section{Metodología}

\section{Método}

Se analiza la marca país desde el año 2001 hasta el año 2017. Según el enfoque, esta investigación es cualitativa, ya que se utiliza el análisis de casos y se evalúa diversos aspectos e implicancias de la publicidad sobre el cantón Cayambe para comprender los significados culturales y métodos publicitarios.

\section{Universo, muestra, análisis de datos}

Los 45 representantes de las empresas suscritas a la Cámara de Turismo de Cayambe son el universo y muestra de la investigación; las personas seleccionadas, mediante muestreo teórico, constituyen el total de casos típico. La técnica para el recojo de información es la encuesta. El objetivo es detectar la necesidad de promocionar la marca país y potenciar el sector empresarial; en el análisis y la interpretación de los resultados se utilizó Excel.

Previo a la encuesta, se entrevistó al director de Interculturalidad del Gobierno Autónomo Descentralizado Intercultural y Plurinacional (GADIP), del municipio de Cayambe, con el fin de conocer los avances del sector público y privado en la publicidad del cantón y el tipo de canales empleados. 


\section{Diagnóstico}

El diagnóstico se realizó con el método histórico-lógico, con el fin de analizar la situación turística de Cayambe, principales componentes y su desarrollado, y el método cualitativo, en función de los resultados de las encuestas.

\section{Situación sociodemográfica.}

El origen histórico de Cayambe y su fundación se basan en la leyenda y en el reconocimiento legal como cantón en la época republicana.

En la leyenda, se conoce que la fundación la realizan cuatro caciques shyris en la época preincaica. Los cayambis viven confederados con los cochasquíes y caranquis, gobernados por Nasacota Puento. A la llegada de los incas, los cayambis dieron una gran batalla antes de ser vencidos, pues se conoce que fue un pueblo orgulloso de su autonomía y sabiduría ancestral.

El reconocimiento legal y la categoría de cantón le fue otorgada mediante Decreto Ejecutivo por el Presidente Provisional de la República, Dr. Luis Cordero, el 23 de julio de 1883.

Cayambe está al noreste de la provincia de Pichincha en Ecuador, representa el 12.5\% del territorio. Según el último censo del 2011, la población del cantón tiene 85795 habitantes; donde 57.95\% corresponde a la población urbana y 42.05\% a la población rural, la mayor parte de origen indígeno. Sin embargo, la organización de la población por asociaciones es prácticamente inexistente en las parroquias rurales (Plan de Ordenamiento Territorial, 2025). Sus principales fuentes de ingreso provienen del sector agrícola (47.7\%), comercio al por mayor y menor (11.9\%), construcción (7.9\%) y otras actividades (6.3\%). La floricultura también es importante, hasta el año 2012 la ciudad tenía el 13.87\% de la producción del país. Asimismo, Cayambe cuenta con industrias y emprendimientos familiares.

El cantón posee diversos tipos de bosques, flora y fauna; además, atractivos naturales, arquitectónicos, gastronómicos y culturales. A pesar de estas potencialidades, que podrían mejorar las condiciones económicas de sus habitantes, se observa que en las parroquias rurales más del 80\% de la población vive en condiciones de pobreza (Alcaldía Metropolitana de Quito, 2015).

Cayambe tiene tres parroquias urbanas: Ayora, Cayambe y Juan Montalvo; y cinco parroquias rurales: Ascázubi, Cangahua, Cusubamba, Olmedo y Otón. El nombre del cantón proviene del volcán Cayambe, que se ubica en la ladera occidental de esta elevación por donde atraviesa la línea equinoccial que le brinda un clima favorable para el desarrollo de vegetación variada.

\section{Atractivos turísticos y culturales.}

Según el informe del Gobierno de Pichincha, el 27\% de atractivos turísticos de la provincia están en la zona norte, precisamente donde se ubican Cayambe y Pedro Moncayo. Entre los atractivos turísticos que tiene están el templo del sol y la luna de Puntiatsil, el monumento a la mitad del mundo conocido como la bola, el Castillo 
de Guachalá, las haciendas Miraflores, Guachalá y Granobles, el petroglifo de la chimba, el casco colonial de la ciudad donde figura el palacio municipal, el museo de la ciudad, la iglesia matriz y el parque central, balnearios de aguas termales de Ishigto, las Golondrinas y Oyacachi, las cascadas del Tingo, las iglesias y templos de la época colonial en todas las parroquias cayambeñas y el elemento simbólico de los cayambeños, el majestuoso nevado Cayambe, el único nevado en el planeta ubicado en la mitad del mundo. Al encontrarse en la avenida de los volcanes alberga al Parque Nacional Cayambe-Coca, Centro Cultural Mamá Tránsito Amaguaña, Hacienda Pesillo, Laguna San Marcos, Complejo Arqueológico Pambamarca. También presenta importantes vestigios culturales como son las ruinas de Pucará, el complejo arqueológico de Pambamarca, Gualimburo y la hacienda Guachalá, así como casas que datan de 1890; fiestas culturales como la de San Pedro y de la Virgen del Carmen.

Cabe mencionar, que para la implementación del turismo comunitario es importante la organización de la población por asociaciones, pero no se registran en estas parroquias (Alcaldía Metropolitana de Quito, 2015).

Los atractivos naturales como la laguna Puruhatag, las aguas termales Las Golondrinas y La Chimba, los páramos de Pesillo, la cima del cerro Cuniburo y el Parque Nacional Cayambe-Coca forman parte del Sistema Nacional de Áreas Protegidas del Ecuador y constituyen el área con mayor diversidad de flora y fauna del país; donde se han identificado 100 especies de plantas endémicas, 106 mamíferos, 395 aves, 70 reptiles y 116 anfibios.

Estos sitios tienen un valor histórico y cultural para la ciudad, así como para la región y el país. Por la diversidad de sus atractivos son considerados propicios para el turismo científico, comunitario y de aventura. Para cubrir las necesidades de los turistas se cuenta con 47 restaurantes (uno de ellos, en la categoría más alta), 14 bares y 19 lugares de alojamiento. Sus productos típicos y únicos de la zona son quesos y bizcochos; y una colada, llamada cariucho, hecha con todos los granos.

En lo cultural, su grupo étnico es el Kayambi. La mayor expresión de la cultura cayambeña se evidencia en los meses de junio y julio, cuando se celebran las fiestas de San Pedro y del sol en la mitad del mundo, esta última resulta de la realidad del mestizaje étnico cultural en Cayambe a lo largo de los siglos, vale decir, lo aborigen y lo castellano. La fiesta del sol de los Cayambis es anterior al Inti Raymi de los incas; se ven toros populares, juegos pirotécnicos, vacas locas, desfiles, comparsas, verbenas, competencias atléticas, hieleros, constituyéndose en una fiesta para todos, donde los personajes de la fiesta entonan canciones y coplas populares al ritmo de guitarras.

Los personajes:

- Diabluma: personaje principal de la fiesta; hombre disfrazado, su rostro está cubierto por una máscara de dos caras con doce cachos (representan los meses de trabajo del año), atravesada por líneas paralelas de colores vivos; además lleva acial y zamarro.

- Aruchico: bailarín y guitarrero de la fiesta, lleva zamarro, campanas, chalinas cruzadas y camisa bordada.

- Huarmi: mujer que baila y canta coplas junto a los aruchicos, lleva anacos, camisón bordado, alpargatas.

- Chinuca: hombre disfrazado de mujer, personaje humorístico de la fiesta. 
- Taquidor: aruchico mayor que dirige y da la voz de canto.

- Payaso: personaje introducido en la época de la conquista.

Los deportes:

Los deportes que se practican en esta ciudad, por su ubicación y por sus sitios turísticos, son el ciclismo de montaña, andinismo, excursionismo, rapel, pesca deportiva y escalada.

\section{Situación turística.}

El número de visitantes a las áreas naturales del Ecuador es irregular. Acuden a parques nacionales, reservas biológicas, ecológicas, faunísticas, de vida silvestre, marina y de recreación. Se incrementó desde el año 2011 al 2015 (Ministerio de Turismo del Ecuador, 2017). Los resultados de las visitas al finalizar el año 2014 evidenciaron un fortalecimiento de las visitas de turistas extranjeros; 35\% más con relación al año 2013. Este impulso al sector turístico a nivel nacional impactó principalmente en el Parque Nacional Galápagos y en la Reserva Ecológica Los Illinizas.

En el caso del Parque Nacional Cayambe Coca, principal atractivo turístico del cantón Cayambe, se observa un decrecimiento del 41\% de visitantes en el año 2014; movimiento contrario a la tendencia a nivel nacional y se evidencia un crecimiento del 19\% al finalizar el año 2015, acorde con la tendencia del país.

Según el Ministerio de Turismo (2015), el movimiento de visitantes nacionales y extranjeros es irregular en esta reserva desde el año 2011 al año 2015, movimiento que es similar al de la Reserva Cotacachi Cayapas y opuesto a los ingresos que se registran en la Reserva Ecológica Antisana y de Los Illinizas. Esta situación, incide en la reducción de alojamientos y establecimientos de comidas y bebidas en el cantón, y como consecuencia, en el número de personas empleadas en estas actividades (ver Fig. 1 y Fig. 2).

Para la Organización Mundial del Turismo (OMT), en el año 2017, la llegada de turistas internacionales a escala mundial fue de 1260000 en el 2015, que es 47 veces mayor a las llegadas registradas en 1950. Los ingresos por concepto de turismo aumentaron a nivel global representando el 7\% de las exportaciones mundiales de bienes y servicios. En Ecuador, el gasto turístico con relación al Producto Interno Bruto (PIB) se incrementó paulatinamente hasta llegar a un 1.6\% en el primer trimestre del año 2017 (Ministerio de Turismo, 2017). Ecuador en 2015 ocupó el sexto lugar entre 13 países respecto al número de visitantes internacionales (OMT).

El Plan Nacional del Buen Vivir contempla, dentro de sus objetivos y estrategias, el cambio de la matriz productiva, para pasar de una estructura productiva basada en la extracción de recursos naturales, a una nueva estructura socioeconómica, sostenible y sustentable orientada al bienestar de todos los ecuatorianos. El plan contempla, dentro de la oferta de servicios, al turismo como un elemento fundamental para esta transición, en especial en las zonas rurales donde se incluyen a la artesanía y pequeñas industrias en un marco de bioconocimiento para el desarrollo territorial. 
Figura 1

Visitas Parque Nacional Cayambe

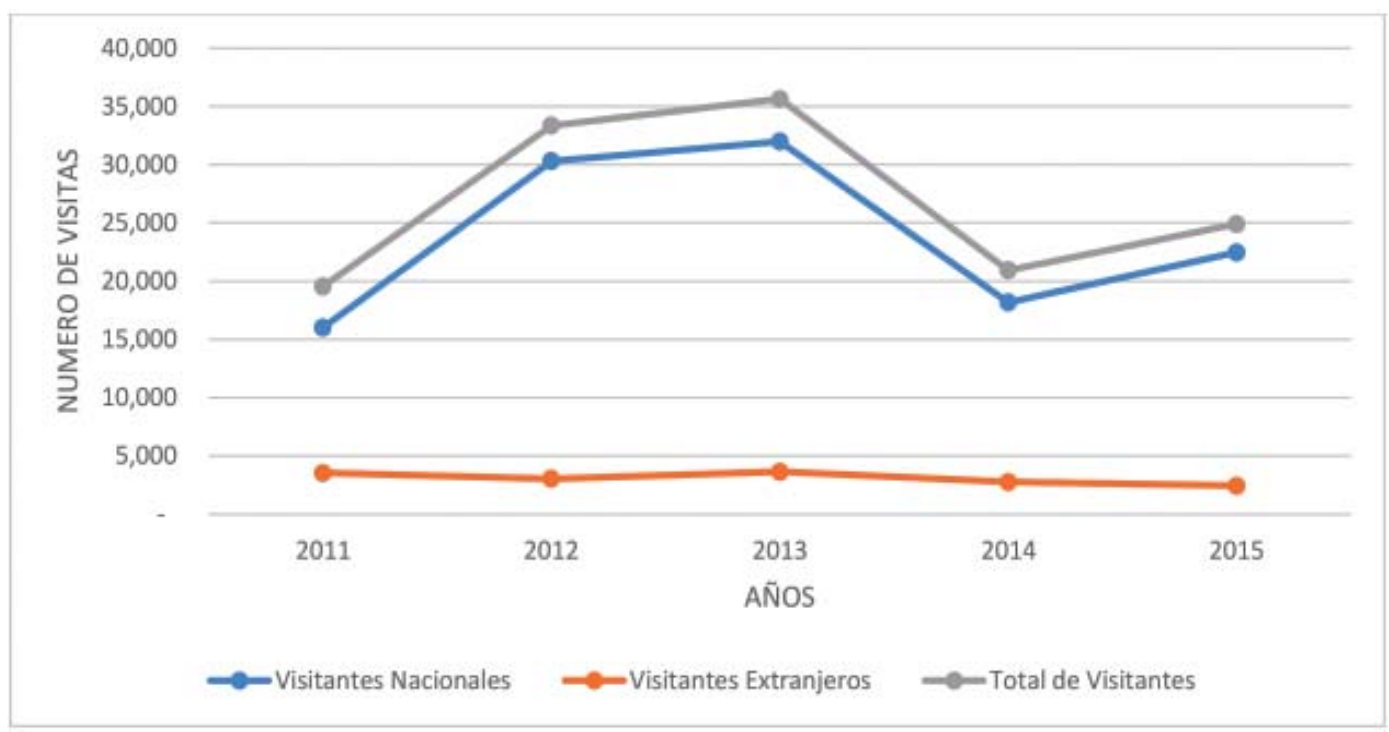

Nota. Elaboración propia.

\section{Figura 2}

Visitas áreas naturales del Ecuador

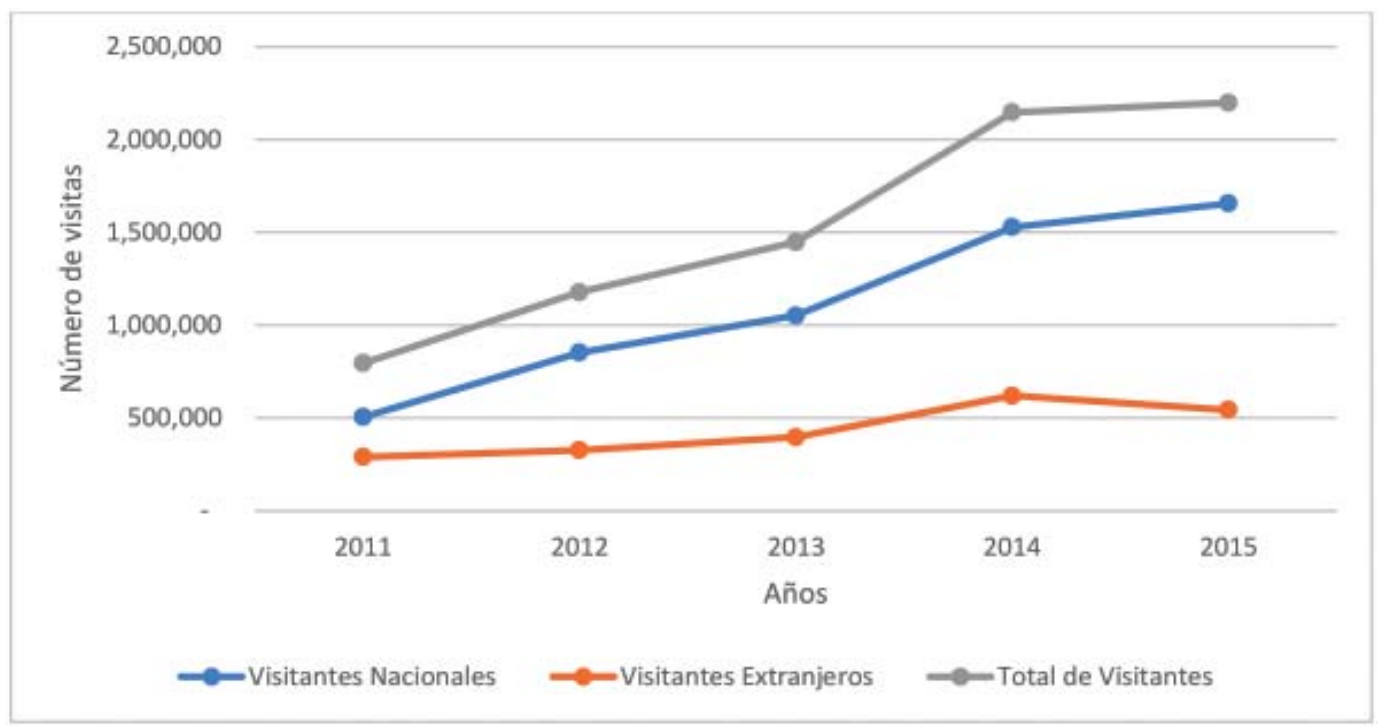

Nota. Elaboración propia. 


\section{Economía.}

El espacio rural de Cayambe es una zona poco poblada, caracterizada por una economía basada en el aprovechamiento de recursos naturales y en la producción de bienes propios del lugar; están apartados de los centros urbanos y son lugares principalmente interiores, no industrializados, por lo que conservan su identidad y su cultura casi intactas (Greciet, 1994). Según la OMT (2017), el turismo rural incluye «las actividades turísticas que se realizan en el espacio rural y que tienen como fin interactuar con la vida rural, conocer las tradiciones y la forma de vivir de la gente y los atractivos de la zona». El agroecoturismo, el ecoturismo y el turismo comunitario son modalidades de turismo que se derivan a su vez del turismo rural (Arauz, 2010).

De acuerdo al Plan de Desarrollo y Ordenamiento Territorial de las parroquias rurales con un alto porcentaje de pobreza, la mayoría de la población son mujeres mestizas y en algunas parroquias con mayoría de población indígena Cayambi.

$\mathrm{Al}$ ser el agroecoturismo un tipo de turismo rural, que consiste en visitar emprendimientos rurales para conocer las actividades agropecuarias y en las que el turista se involucra, se pueden generar actividades asociadas como hacienda-hotel, posada, restaurante típico, ventas directas del productor, artesanías y otras de recreación ligadas a la vida cotidiana de los pobladores del campo (Cedeño, como se citó en Garibay y Jyoti, 2006). En este sentido, existen iniciativas agroecoturísticas de la Dirección de Turismo del Gobierno Autónomo Descentralizado Municipal de Cayambe que buscan fortalecer la ruta de la leche y la ruta de las flores, impulsadas por la feria nacional del queso, ganadería y productividad y la asociación de productores y/o exportadores de flores del Ecuador (Expoflores), respectivamente.

También, están las producciones de lácteos y biscochos, en su mayoría a cargo de grupos familiares y con inversión de la empresa privada, sobre todo en los lacteos. Los grupos familiares en el cantón carecen de una estructura empresarial, razón por la cual es fundamental el desarrollo de programas de capacitación en la formación de microempresas y de asociaciones en las comunidades rurales, donde la población económicamente activa se dedica a actividades agropecuarias. Es necesario diversificar las fuentes de ingreso económico y mejorar la calidad de vida de sus habitantes mediante el desarrollo de actividades turísticas.

La escasa estructura microempresarial en las comunidades del cantón es una de las razones para la realización del presente trabajo. En vista de lo cual, se aplicaron encuestas a los representantes de las empresas suscritas a la Cámara de Turismo de Cayambe, quienes reflejan la necesidad de varios sectores de la población; sin embargo, es importante que para futuros estudios se considere incluir a los microempresarios. Con la información es posible promover actividades en el turismo y generar ingresos económicos en el cantón, mejorando la calidad de vida de sus habitantes.

\section{Problemas de infraestructura.}

Un aspecto que afecta a ciudades, como la cabecera cantonal, son los pasos laterales construidos por el gobierno del Ecuador que acortan los tiempos de viaje de las personas a otros destinos, descongestionan el tránsito de vehículos, eliminan el tráfico pesado de las ciudades y mejoran la calidad de las carreteras. Esto 
repercute en el flujo vehicular que circunvala y desvía el tráfico de ciudades como Quevedo, Santo Domingo, Daule, Chone, El Carmen, Latacunga, Salcedo, entre otras. Esta reorganización del tránsito impacta a ciudades que se consideraban de entrada y salida vehicular obligatoria; que actualmente son consideradas como ciudades de paso. Es el caso de Cayambe, donde se observa que los visitantes no se quedan a realizar actividades turísticas.

Si bien, hay mejora en la infraestructura de las carreteras que conectan al cantón con otros cantones aledaños, las parroquias requieren atención de vías, caminos vecinales y señalización para facilitar la llegada de los visitantes.

\section{Hallazgos}

\section{Encuesta y entrevistas}

Se utilizaron las técnicas de observación, entrevista y encuesta para el diagnóstico y recolección de datos. En un principio se analizó la historia y material cinematográfico del cantón Cayambe. Posteriormente, se entrevistó al director de interculturalidad del Gobierno Autónomo Descentralizado Intercultural y Plurinacional (GADIP) del Municipio de Cayambe y se aplicaron los cuestionarios a los 45 representantes de las empresas suscritas a la Cámara de Turismo de Cayambe.

El 93.33\% de los encuestados sostiene que hace falta promocionar el cantón Cayambe, lo que revela la poca importancia en la gestión -tanto pública como particular-para publicitar el turismo del cantón hasta el momento. El 96\% de representantes empresariales encuestados concuerdan en que les gustaría ver un spot que exponga la historia, cultura, sitios turísticos y gastronomía de Cayambe; y 91\% prefiere que el spot publicitario tenga una duración entre 30 segundos y 1 minuto; además, reconocen que falta publicidad.

Todos los encuestados convergen en que Cayambe es un cantón turístico. Actualmente, 58\% de la oferta del turismo se enfoca en el desarrollo de turismo comunitario, que se divide en turismo de aventura y en turismo cultural, incluyendo actividades de interés gastronómico. El turismo natural que abarca actividades de agroecoturismo y ecoturismo abarca el $42 \%$ de la oferta turística del cantón.

En su mayoría, el sector empresarial tiene interés en que se promocione el potencial turístico de Cayambe y 85\% de los encuestados desean que el cantón se promueva mediante Internet y televisión.

Estos resultados están concatenados con las afirmaciones del Director de Interculturalidad del GADIP Cayambe acerca de la falta de turismo en el cantón:

Hace falta una gestión pública en el tema de turismo, ha existido abandono y desinterés en promover políticas que apoyen a generar esto; todos las acciones e iniciativas que se tomen son válidas pues aportan y suman, pero mientras no exista un compromiso desde las autoridades que sea sostenible en el tiempo, es complicado. (comunicación personal) 


\section{Discusión}

\section{Marca ciudad}

Según Loreto y Sanz (2005, p. 6), marca ciudad, es el «nombre, término, símbolo o diseño, o combinación de ellos que trata de identificar las características de la ciudad y diferenciarla de otras ciudades».

Cayambe no ha concebido la gestión de marca ciudad. Es así que su imagen y eslogan han variado de acuerdo a los cambios políticos. No obstante, se rescata que en 2012, se creó los términos «Ciudad del sol» y «Mitad del Mundo» y se elaboró un spot corto e imagen representativa; en 2013 el Ministerio de Turismo lanzó un video promocionando a Pichincha, nombrando a todos sus cantones, entre ellos, Cayambe (no hubo eslogan); en 2016, la página web de la ciudad se renovó y se ensayaron algunos nombres: Una puerta al turismo y Un atractivo turístico, en los dos casos se incluyó información de gastronomía, iglesias y parques como parte de la identidad de la ciudad (no se visualiza alguna campaña específica o gestión de marca, aunque sí cambios en las imágenes).

De acuerdo a López (2004, p. 4), para establecer la identidad de una marca se debe buscar responder a las siguientes preguntas:

1. ¿Cómo se define la propia ciudad?

2. ¿¿ué elementos la identifican?

3. ¿Con quién se compara?

4. ¿Qué utiliza para describirse?

En el punto uno, según los resultado de las encuestas, se define la ciudad como turística, tradicional y cultural. La historia es importante para la comunidad, además de sus costumbres, por lo que se debe conservar las tradiciones a través de las generaciones, así como reconocer a sus íconos culturales.

Como respuesta a la segunda y cuarta interrogante, Cayambe se identifica con dos premisas: Cayambe en la mente de las personas y Cayambe como símbolo, que se fundamenta sobre la base de los siguientes significados: atributos, beneficios, valor, cultura y personalidad (Kapferer, 1992).

Hay muchos referentes de marca ciudad/país que usaron estos significados. Bolivia, en 2016 realizó una campaña, donde destacaron: mística, aventura, paisaje y cultura. España también lo hizo con el eslogan «Necesito España» y posicionando a la ciudad dentro del arte y la cultura. Inspired by Iceland, reforzó los atributos al atraer las sensaciones e inspiraciones del país. Perú, ha construido valor país sobre el orgullo de su cultura indígena. Brasil se ha enfocado en la diversidad social. Argentina en la renovación y la recuperación de la riqueza del turismo nocturno.

Como resultado del diagnóstico y luego de identificar los elementos identitarios de la ciudad, se concluye que cultura, valores y atributos son esenciales para Cayambe. En la construcción del eslogan «Te quiero 
Cayambe» se puede identificar el objetivo de la marca ciudad, enfatizando en una emoción de apego hacia una ciudad que ofrece los significados de identidad elegidos. La expresión te quiero y su significado reforzado por los sentimientos, implícitamente busca que sus visitantes se enamoren de la ciudad y puedan expresar el eslogan como parte de su experiencia.

Para reforzar el mensaje comunicacional, se creó un logo compuesto por los siguientes elementos: línea dibujada de la silueta del volcán de color azul. En el centro del volcán un círculo espiralado que representa el reloj inca situado en la ciudad. La paleta de colores usado es de tonos brillantes y fuertes. Estos colores también se incorporan en la tipografía del nombre de la ciudad, Cayambe.

En la pregunta cuatro se contempla a sus competidores directos y grupo objetivo. Al analizar la competencia de Cayambe se puede identificar a Sangolquí y Machachi; sin embargo, ninguna de las dos ciudades dentro de la provincia de Pichincha se relacionan con el volcán, la reserva y la mitad del mundo. En la misma provincia, podría ser considerada su competencia, aunque es una ciudad que, como capital, ha trabajado más la gestión de su marca, tiene más reconocimiento internacional y además es la ciudad más relacionada con la mitad del mundo; aunque no se le considera como parte de la competencia primaria. Cayambe por su número de habitantes, debe competir con ciudades más cercanas a su realidad, como Machachi y Sangolquí, ciudades que aún no tienen una marca ciudad definida.

El grupo objetivo de la ciudad son los visitantes residentes, potenciales y los inversionistas. Para efectos de la estrategia se considera al ciudadano como cliente.

Por consiguiente, las fortalezas de Cayambe se centran en el posicionamiento local de tres tipos de turismo: ecológico, cultural y científico. Tipos turísticos que definen a la ciudad. Se concibe que el ecoturismo o también considerado turismo ecológico, para esta propuesta publicitaria, contempla viajes o visitas a las áreas naturales relativamente inalteradas (incluyendo las áreas protegidas). El objetivo es diverso, como disfrutar, apreciar y estudiar los atractivos naturales: paisajes, flora y fauna silvestres locales; también lugares con riqueza cultural que promuevan la conservación. El turismo cultural se centra en lugares históricos de la ciudad como el reloj inca Quitsato, que también aporta al turismo científico al ser considerado la mitad del mundo. Siendo lo más importante la participación activa de la población local (Ceballos-Lascurain, como se citó en Parkes,1990).

\section{Estrategia publicitaria}

El éxito de una marca en un mercado depende de dos variables: la frecuencia de contacto con la marca, de los potenciales consumidores y la experiencia positiva que tengan con la marca (Marzano, 2012). Por ello, se crea un plan publicitario para difundir la marca, que incluye un producto audiovisual con los elementos representativos de Cayambe. Este video será el producto comunicacional que inicie la interacción con la audiencia en los diferentes canales. Se pretende proyectar con las imágenes una narrativa de experiencia turística milenaria y ambiental que en el consumidor visual, turista, e incluso el habitante, despierte su interés por ser parte de la historia, cultura, aventura y ciencia de Cayambe: cuatro ejes de la experiencia. 
En este contexto, el contenido audiovisual para el spot de 30 segundos se define bajo los siguientes parámetros técnicos:

- Sinopsis. El cantón Cayambe tiene una arquitectura colonial, representa un legado histórico por lo que existe un sentimiento de identidad con sus generaciones pasadas, sitios naturales, cultura y gastronomía.

- $\quad$ Log Line. Cayambe, el valle del sol, milenario y turístico.

- $\quad$ Story-Line. Cayambe, a los pies del nevado Cayambe, encierra historia, cultura, aventura y ciencia.

- Argumento. El cayambeño y cayambeña realizando sus actividades cotidianas, en medio de una demografía natural, con el volcán Cayambe vigilante que sorprende con su majestuosa belleza y conjuga con el misterio del reloj en la mitad del mundo. La alegría de sus habitantes, su gastronomía y música armonizan las actividades cotidianas, así como las fiestas tradicionales.

Los atractivos turísticos que se visualizan en el spot son:

- $\quad$ El templo del sol y la luna de Puntiatsil

- La reserva ecológica Cayambe-Coca

- $\quad$ El monumento en la mitad del mundo conocido como la bola

- El casco colonial de la ciudad donde figura el palacio municipal, el museo de la ciudad, la iglesia matriz y el parque central

- Balnearios de aguas termales de Ishigto, las Golondrinas y Oyacachi

- $\quad$ Las cascadas del Tingo

- $\quad$ Las iglesias y templos de la época colonial en todas las parroquias cayambeñas

- $\quad$ Nevado y volcán Cayambe

- Diabluma, el personaje principal de la fiesta

- $\quad$ Bizcochos

- Manjar de leche

\section{Propuesta estética y técnica.}

El formato HD (1920*1080) permite mostrar imágenes en alta definición; se exporta una versión en menor calidad para usar en redes sociales; ratio o relación de aspecto 16:9 que brinda más información en el encuadre; aspecto de las pantallas en las que se proyecta el spot 24 cps (cuadros por segundo). Uso de soportes como cámara sobre trípode, dron y grúa; imágenes fijas, aéreas y en movimiento que permitan una narrativa visual dinámica, predominando los planos generales (PG).

Manejo de colores cálidos y propios de la bandera del cantón - de acuerdo al planteamiento de la psicología del color- que se relaciona con el entorno y con la experiencia que se genera en las personas; uso de colores 
cálidos que generan la sensación de movimiento, alegría, actividad, acción, etc. Musicalización, mediante una pista basada en el uso de instrumentos de viento. Vestimenta y maquillaje de los personajes naturales, evitando la manipulación. Postproducción, con un montaje rítmico para que se desarrolle la narración y el concepto.

\section{Estrategia comunicacional.}

El canal utilizado por el Gobierno Autónomo de Cayambe es la página web institucional y redes sociales como Facebook; una página denominada Gad Cayambe Coordinación General no tiene registro de actividad desde su creación. Los ciudadanos de la ciudad crearon un grupo en la misma plataforma llamado Proyecto Gad Cayambe que sirve de interacción entre sus habitantes, pero no tiene uso publicitario de la marca ciudad. Esto demuestra un vacío comunicacional, tanto en el mensaje como en el uso de los canales o plataformas.

Se entiende esta propuesta de narrativa transmedia como «una narración que involucra varios medios» (Jenkins y Thorburn, 2003). Cuando se habla de canales de comunicación -desde las teorías de comunicación de la Escuela Norteamericana- se analizan los diferentes medios. De la misma manera, se considera importante establecer los códigos culturales del emisor y receptor desde la semiótica y el discurso.

Es así que los códigos culturales de Cayambe como ciudad y los de sus habitantes tienen como objetivo presentar a la ciudad y su cultura tanto a los locales como a los foráneos. Tener en claro estos códigos es importante, así como lograr proyectarlos. En este sentido, los supuestos sociales también han sido analizados, destacando los económicos, culturales y turísticos de la zona para construir el discurso en el spot publicitario.

\section{Tabla 1}

Secuencia de escenas

\begin{tabular}{rll}
\hline Sec. & Nombre de la secuencia & Objetivo dramatico \\
\hline 1 & Logo universidad & Introducción \\
2 & Ubicación Cayambe (nevado) & Establecer tiempo y espacio \\
3 & Personas (5 momentos) & Mostrar intergeneracionalidad y \\
& & espacios turísticos \\
4 & Campo. Dron & Mostrar naturaleza \\
5 & Iglesia & Exponer arquitectura y religiosidad \\
6 & Camino & Revelar la carretera \\
7 & Reloj solar & Manifestar la idiosincrasia \\
8 & Gastronomía & Mostrar riqueza comida \\
9 & Diabluma & Cultura \\
13 & Créditos & Fin \\
\hline
\end{tabular}

Nota. Elaboración propia. 
Para determinar la estrategia es necesario aplicar los siete principios de la narrativa de Jenkins y Thorburn (2003):

- Expansión vs. profundidad. Expansión, por la participación de la audiencia al difundir contenidos mediante distintos canales, y profundidad, por la acción de la audiencia en búsqueda de más información. En esta propuesta, la expansión y profundidad son importantes, ya que el grupo objetivo es local e internacional. La audiencia de estos dos grupos tiene acceso a los distintos canales tecnológicos, especialmente a las redes sociales, donde Facebook e Instagram son considerados parte de la expansión, mientras que Snapchat, Pinterest, Twitter y Google+ se usan como profundidad, ya que la audiencia joven y adulta busca información en estas plataformas. En este sentido, la expansión y profundidad van de la mano.

- Continuidad vs. multiplicidad. Los universos creados en los canales mencionados en expansión vs. profundidad tienen coherencia y credibilidad. La multiplicidad se basa en dos sentidos: los visitantes como habitantes reconocen los lugares resaltados en el spot publicitario y pueden construir su propia historia en estos escenarios, por ejemplo, grabando un pequeño video en el sitio. Esto permite las versiones alternativas de los personajes.

- Inmersión vs. extracción. En la inmersión la audiencia puede ser parte del universo transmedia al interactuar en los canales y ser protagonista de las historias, es decir, ser activo en todo este universo con sus likes, comentarios y feeds. Se promueve que la audiencia forme parte al integrar su vida cotidiana y así lograr la extracción.

- Construcción de mundos. Relacionado con lo explicado en la continuidad vs. multiplicidad, ya que se basa en las experiencias del mundo real y el mundo digital. La inmersión y extracción están implícitas.

- Serialidad. La historia subida por la audiencia, contando su propia experiencia en los escenarios de Cayambe, sirve como fragmentos para la escaleta de una sola historia, donde el referente es la experiencia personal. Se transmite en fragmentos, de acuerdo a las múltiples entregas en diferentes medios, como Facebook, Instagram y Snapchat, al ser las plataformas disponibles para videos cortos y que usa la audiencia; de esta manera se logra una ruptura del arco narrativo

- $\quad$ Subjetividad. Esto se determina por los puntos anteriores, donde se indaga la historia mediante diferentes personajes y puntos de vista.

- Ejecución. El trabajo creado por los visitantes se convierte en parte de la propia narrativa transmedia. Logrando el objetivo principal de la transmedia, la participación del público y la generación de contenido.

La convergencia mediática es implícita en la explicación de los siete principios de la propuesta, ya que usa múltiples plataformas mediáticas. La cultura participativa también es un punto importante que se considera en la propuesta, al ser los visitantes los que construyen historias narrativas con significado. De esta manera se aprovecha la interacción para lograr una inteligencia colectiva; se convierten las acciones e interacciones en un proceso colectivo. 


\section{Conclusiones}

Aunque Ecuador no tiene una política en la construcción de marca para las ciudades pequeñas, Cayambe es un referente para las ciudades vecinas que también son consideradas potenciales turísticos. Es preciso tener en cuenta que la cultura y la naturaleza son las fortalezas para el desarrollo de marcas en la zona norte del Ecuador.

La situación económica de Cayambe, así como su estructura, códigos sociales culturales y situación turística, son una base para la propuesta de gestión de marca ciudad. Al ser una ciudad pequeña y no tener constituida una política clara de identidad mediante una imagen, se inicia el trabajo con la identificación de sus valores identitarios tangibles e intangibles y el concepto principal de su marca.

Con los resultados se establecen los parámetros en los que se enfoca la marca ciudad, así como todo el proceso de creación del spot publicitario que visualiza este nuevo concepto de Cayambe por medio de un mensaje comunicacional: Te quiero Cayambe.

1. La creación de la marca Cayambe, así como el spot publicitario, son el inicio de un trabajo de gestión de marca, donde las acciones visuales y comunicativas se basan en la estrategia de narrativa transmedia, aplicada en la publicidad de vanguardia. Los siete principios de transmedia son la base del desarrollo de cada actividad transmedia (Jenkins y Thorburn, 2003).

2. Este es un trabajo novedoso en el Ecuador, ya que aborda el tema de la marca ciudad de forma integral, con un método aplicable y práctico, considerando a los usuarios como emisores y receptores de la narrativa transmedia.

3. Ecuador y sus ciudades, tienen cuatro ejes turísticos: historia, cultura, aventura y ciencia. La experiencia del consumidor (turista interno y externo) debe incluirlos.

4. Este modelo puede aplicarse en otras ciudades pequeñas del Ecuador, ya que existen los recursos naturales y culturales para la construcción de sus respectivas marcas ciudad, y para el desarrollo del turismo. Compromiso que no solo debe atribuírsele al gobierno local, sino también a sus habitantes, ya que la marca no es un concepto aislado, es parte de la identidad de ellos, actores principales en la aplicación de estrategias relacionadas con transmedia. 


\section{Referencias}

Alcaldía Metropolitana de Quito. (13 de febrero de 2015). Plan de Desarrollo y Ordenamiento Territorial. https://www.quito.gob.ec/ documents/PMDOT.pdf

Arauz, I (2010). Análisis del Sistema Turístico del Cantón de Buenos Aires: Insumo para un Diseño de Plan de Desarrollo en Turismo Rural. http://www.eumed.net/libros-gratis/2012b/1199/index.htm

Bogart, L. (1985). Technologies of Freedom: On Free Speech in an Electronic Age. Ithiel de Sola Pool. American Journal of Sociology, 91(2), 472-474.

Economic Impact Reports. (2017). World Travel Tourism Council. https://wttc.org/Research/Economic-Impact

Garibay, S. V. y Jyoti, K. (2006). Primer Encuentro latinoamericano y del caribe de productoras y productores experimentadores y de investigadores en agricultura orgánica, 26 al 29 de septiembre de 2006, Managua, Nicaragua [Memorias]. Research Institute of Organic Agriculture FiBL, Frick, Switzerland.

Greciet, P. (1994). Turismo rural. Ministerio de Agricultura, Pesca y Alimentación.

Jenkins, H. y Thorburn, D. (2003). Introduction: The digital revolution, the informed citizen, and the culture of democracy. Democracy and new media, 1(17).

Kapferer, J. N. (1992). La marca, capital de la empresa (n. ${ }^{\circ}$ hal-00788642).

López, J. M. (2004). Planificación estratégica y marketing de lugares. Marketing de Ciudades y Desarrollo Urbano [Comunicación presentada en Seminario virtual].

Loreto, M. y Sanz, G. (2005). Evolución de la terminología del marketing en ciudades. Universidad de Alcalá (pp. 3-6).

Marzano, G. (2012). Marca país: un enfoque metodológico. Revista Polemika, 19(3), 26-29.

Ministerio de Turismo. (2017). Rendición de cuentas. Ejes de acción. https://drive.google.com/file/d/1kPpeh_jTPaJEPfYAmqVnwR8VFAVVd9v/view

Ministerio de Turismo del Ecuador. (2017). Boletín de Estadísticas Turísticas (2011-2015). http://servicios.turismo.gob.ec/descargas/ Turismo-cifras/AnuarioEstadistico/Boletin-Estadisticas-Turisticas-2011-2015.pdf

Orgaz, F. (2013). El turismo comunitario como herramienta para el desarrollo sostenible de destinos subdesarrollados. http:// www.redalyc.org/html/181/18128245006/

Organización Mundial del Turismo (OMT). (2017). Panorama OMT del Turismo Internacional. https://www.e-unwto.org/doi/pdf/10.18111/ 9789284419043

Parkes, K. C. (1990). Additional Records of Birds from the Distrito Federal, Mexico, including a Possible Hybrid Spizella. The Condor, 92(4), 1080-1081.

Lourdes Calderón Garrido

Universidad Tecnológica Israel, Artes y Humanidades. Magíster en Comunicación y especialista en comunicación corporativa. Autora de veinte libros de literatura, colección Tesoro de Letras. Articulista y blogger. Docente en áreas de Comunicación Estratégica, Liderazgo, Gerencia de Medios, Comunicación Corporativa y Teorías de la Comunicación por seis años en universidades de Ecuador. Experiencia en cargos jerárquicos en comunicación en la empresa privada y pública. Redactora, periodista y especialista en creación de campañas y branding. Ganadora del premio mejor artículo Fundación Somos 2016, EE.UU.

Icalderon@uisrael.edu.ec

ORCID: 0000-0002-8901-1413

Diana Gabriela Toapanta Espín

Universidad Tecnológica Israel, Administración. Máster en Economía de Macquarie University Australia con estudios de pregrado en Ingeniería Comercial en Administración Financiera y Contabilidad Pública Autorizada. Experiencia laboral en planificación y control de gestión, elaboración de reportes, análisis y evaluación de información comercial y financiera en diversas ONG y banca privada. Docente investigadora de Economía y Sociedad, y Microeconomía en la Universidad Tecnológica Israel.

dtoapanta@uisrael.edu.ec

ORCID: 0000-0003-1680-8584 